\title{
PENGEMBANGAN APLIKASI PENGENALAN ALAT MUSIK TRADISIONAL JAWA TIMUR MENGGUNAKAN TEKNOLOGI AUGMENTED REALITY BERBASIS ANDROID
}

\author{
Farhan Eka Saputra, Agung Panji Sasmito, Abdul Wahid \\ Program Studi Teknik Informatika S1, Fakultas Teknologi Industri \\ Institut Teknologi Nasional Malang, Jalan Raya Karanglo km 2 Malang, Indonesia \\ farhaneka0708@gmail.com
}

\begin{abstract}
ABSTRAK
Sejauh ini alat musik tradisional cenderung kurang diminati oleh kalangan anak-anak. Hal ini dikarenakan kurangnya sarana dan prasarana, seperti halnya sarana prasarana pendidikan disekolah yang tidak ada fasilitas untuk mempelajari atau melestarikan alat musik tradisional. Kurangnya pengenalan dan sosialisasi akan budaya indonesia di masyarakat, merupakan salah satu faktor yang penting mengapa kurangnya minat generasi muda terhadap mengenalnya alat musik tradisional (Waskito, 2018). Pada penelitian ini, penulis merancang dan membangun Aplikasi Pengenalan Alat Musik Tradisional Jawa Timur menggunakan Teknologi Augmented Reality berbasis Android. Metode yang digunakan pada penelitian ini adalah Research and Development dengan tujuan mengembangkan aplikasi Pengenalan Alat Musik Tradisional Jawa Timur Menggunakan Teknologi Augmented Reality berbasis Android. Hasil pengujian fungsional, Pengembangan aplikasi pengenalan alat musik tradisional Jawa Timur menggunakan Teknologi Augmented Reality berbasis Android dapat dioperasikan dan digunakan secara optimal. semua tampilan background, menu, button dan fitur-fitur yang ada pada aplikasi dapat berjalan dengan lancar dan optimal pada tiga Smarthphone yaitu Samsung A20, Xiaomi Redmi 4X, dan Realme 5.
\end{abstract}

Kata Kunci : Augmented Reality, Alat Musik, Jawa Timur

\section{PENDAHULUAN}

Secara umum, alat musik merupakan suatu benda yang digunakan oleh manusia untuk membantu melakukan suatu pekerjaan. Istilah "musik" berasal dari bahasa Yunani yakni "muse" yang artinya adalah sebutan untuk dewi - dewi yang memiliki tugas sebagai penanggung jawab terhadap suatu seni dan juga ilmu pengetahuan (situs Pendidik, 2019). Seni musik adalah seni yang berhubungan dengan alat-alat musik dan irama yang keluar dari alat musik. Dalam perjalanannya, seni musik dapat berpadu dengan seni suara (vokal), sehingga timbul suara oral (vokal) yang diiringi alat musik (Hirzi, 2007).

Dewasa ini, minat anak-anak dalam mempelajari alat musik tradisional adalah rendah, kendala yang dihadapi dilihat dari segi anak biasanya berasal dari minat anak terhadap metode pendidikan seni musik yang didapatkannya (Yuni, 2016). Kurangnya pengenalan dan sosialisasi akan budaya indonesia di masyarakat, merupakan salah satu faktor yang penting mengapa kurangnya minat generasi muda terhadap mengenalnya alat musik tradisional (Waskito, 2018). Untuk menciptakan generasi yang cerdas dan berkualitas, pendidikan harus dilakukan sejak dini. Pelajaran musik dapat melatih saraf motorik anak dalam bergerak, dapat memperluas dan memperkuat daya ingat anak sehingga akan membantu pengembangan kemampuan berbahasa anak, serta dapat meningkatkan tingkat konsentrasi (Ulfa dkk).

Saat ini, teknologi semakin berkembang, termasuk teknologi dalam penyampaian informasi.
Salah satu teknologi yang sering dipergunakan dalam penyampaian informasi adalah Augmented Reality. Keunggulan dari teknologi Augmented Reality adalah dapat dioperasikan pada smarthphone dan konsol game serta efektif digunakan sebagai media pembelajaran, sehingga informasi akan lebih mudah tersampaikan (Situs Itgenic, 2020).

Berdasarkan paparan tersebut, muncul sebuah gagasan untuk memperkenalkan anak-anak terhadap alat musik tradisional Jawa Timur. Oleh karena itu, melalui penelitian ini penulis menggagas pengembangan Aplikasi Pengenalan Alat Musik Tradisional Jawa Timur Menggunakan Teknologi Augmented Reality berbasis Android. Dengan adanya aplikasi ini, diharapkan dapat menimbulkan rasa ketertarikan bagi anak-anak untuk menghidupkan dan melestarikan alat musik tradisional.

\section{TINJAUAN PUSTAKA}

2.1. Penelitian Terdahulu

Penelitian Rawis dkk (2018) dengan judul Penerapan Augmented Reality Berbasis Android Untuk Mengenalkan Pakaian Adat Tountemboan. Meghasilkan sebuah media informasi pengenalan pakaian adat Tountemboan dengan menggunakan teknologi Augmented Reality User Defined Target yang memungkinkan menambahkan objek virtual pada lingkungan nyata. Penelitian dilaksanakan dengan menggunakan metode Markerless Augmented Reality. Hasil penelitian menunjukkan bahwa Aplikasi Augmented Reality Pakaian adat Tountemboan berjalan pada sistem operasi android 
dimana pada antarmuka pengguna dapat memilih scene Mulai, Panduan, Tentang, dan Keluar.

Penelitian Raranta dkk (2017) dengan judul Pengenalan Teks pada Objek-Objek Wisata di Sulawesi Utara dengan Teknologi Augmented Reality. Menghasilkan sebuah perancangan aplikasi berbasis android dengan menggunakan teknologi Augmented Reality untuk menampilkan terjemahan Bahasa daerah di tempat wisata menjadi Bahasa Inggris dan Mandarin. Penelitian dilaksanakan dengan menggunakan metode pengembangan perangkat lunak Multimedia Development Life Cycle (MDLC). Hasil penelitian menunjukkan bahwa Tampilan Menu Utama, Tampilan menu tempat wisata, Tampilan informasi tempat wisata, Alpha Testing berjalan dengan baik.

Penelitian Lamonge dkk (2017) dengan judul Rancang Bangun Aplikasi Game Augmented Reality Permainan Tradisional Sulawesi Utara Dodorobe. Menghasilkan sebuah permainan Tradisional Sulawesi Utara Dodorobe dalam bentuk Augmented Reality dengan menggunakan metodologi Extreme Programming $(X P)$. Hasil penelitian menunjukkan bahwa Tampilan Splash Screen, Tampilan Gameplay game Dodorobe AR, Tampilan Game Over, Tampilan How to play, Tampilan HighScore dapat dimainkan.

Penelitian Apriyani \& Gustianto (2015) dengan judul Augmented Reality sebagai Alat Pengenalan Hewan Purbakala dengan Animasi 3D menggunakan Metode Single Marker. Hasil penelitian menunjukkan bahwa Tampilan Aplikasi augmented reality alat peraga pengenalan hewan purbakala sudah menarik. Dari hasil persentase, responden yang menyatakan sangat setuju sebanyak $74 \%$, setuju sebanyak $23 \%$, $3 \%$ kurang setuju dan tidak setuju $0 \%$. Maka dapat disimpulkan bahwa tampilan aplikasi Augmented Reality Sebagai Alat Peraga Pengenalan HewanHewan Purbakala Dengan Animasi 3D Menggunakan Metode Single Marker sudah menarik.

\subsection{Dasar Teori}

\subsubsection{Augmented Reality}

Augmented Reality (AR) adalah bagian dari Environment Reality (ER) atau yang dikenal juga sebagai Virtual Reality (VR) (Azuma, 1997). Augmented Reality (AR) memiliki kemampuan untuk melakukan komunikasi visual seperti tulisan bentuk atau gambar dari komputer virtual ke dalam dunia nyata. Antarmuka AR memungkinkan pengguna melihat dunia nyata bersamaan dengan citra virtual yang terletak pada suatu lokasi tempat dan objek nyata. Antarmuka AR meningkatkan pengalaman dunia nyata, tidak seperti antarmuka VR yang menarik pengguna dari dunia nyata dan masuk ke layar visual (Billinghurts, 2002).

Selain menambahkan benda maya dalam lingkungan nyata, Augmented Reality juga berpotensi menghilangkan benda-benda yang sudah ada. Menambah sebuah lapisan gambar maya dimungkinkan untuk menghilangkan atau menyembunyikan lingkungan nyata dari pandangan pengguna. Misalnya, untuk menyembunyikan sebuah meja dalam lingkungan nyata, perlu digambarkan lapisan representasi tembok dan lantai kosong yang diletakkan di atas gambar meja nyata, sehingga menutupi meja nyata dari pandangan pengguna. Augmented Reality dapat diaplikasikan untuk semua indera, termasuk pendengaran, sentuhan, dan penciuman. Selain digunakan dalam bidang-bidang seperti kesehatan, militer, industri manufaktur, Augmented Reality juga telah diaplikasikan dalam perangkat-perangkat yang digunakan orang banyak, seperti pada telepon genggam (Setiawan dkk, 2016).

Pada garis besarnya perbedaan Virtual Reality dan Augmented Reality terletak pada bagian interaksi terhadap pengguna. Tujuan utama dari pembagunan teknologi Augmented Reality sendiri yaitu untuk memberikan sebuah pengertian dan informasi dalam dunia nyata, dimana Augmented Reality mengambil dasar yang terdapat pada dunia nyata, lalu sistem tersebut akan menambahkan data kontekstual agar lebih memperjelas pemahaman seseorang terhadap informasi yang akan diserap (Ginting, Sofyan).

\subsubsection{Marker Based Tracking}

Marker Based Tracking berdasarkan dari teknologi Augmented Reality dihadirkan dari gabungan teknologi computervision dan image processing yang mencari informasi dari sebuah gambar secara langsung (Oktavia dkk, 2019). Dimana marker merupakan gambar 2D yang didesain baik secara khusus ataupun tidak, marker dibutuhkan untuk memunculkan objek 3D yang akan dihadirkan setelah proses tracking dan positioning dilakukan (Khusnul, 2014).

Komputer akan mengenali posisi dan orientasi marker lalu menciptakan objek virtual 3D. Marker akan terekam melalui kamera real time. Kemudian marker digunakan untuk mengenali objek yang akan ditambahkan. Objek yang ditambahkan akan diproses menggunakan komputer dan webcam yang kemudian ditampilkan dalam layar maupun peralatan display khusus melalui pengenalan sebuah marker (Djuniharto, 2013). Alur sistem pada metode Marker Based Tracking dapat dilihat pada Gambar 1.

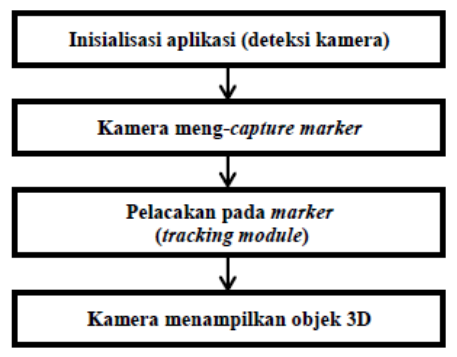

Gambar 1. Alur sistem metode Marker Based Tracking

\subsubsection{Pemrograman Android}

Pemrograman Android adalah pemrograman berbasis Java untuk membuat aplikasi pada device 
smartphone, tablet maupun device lainnya yang menggunakan sistem operasi berbasis Android. Java adalah bahasa pemrograman yang dapat dijalankan diberbagai perangkat komputer, termasuk pada ponsel. Dikembangkan oleh Sun Microsystem dan dirilis pada 1995 (Kurniawan dkk, 2011). Komponen aplikasi adalah blok buildung penting aplikasi Android. Berikut merupakan empat komponen utama yang dapat digunakan dalam aplikasi Android.

1. Activites merupakan Komponen UI dan menangani interaksi pengguna ke layar Smartphone.

2. Services merupakan Menangani proses latar belakang yang terkait dengan aplikasi.

3. Broadcast Receivers merupakan Menangani komunikasi antara Android OS dan aplikasi.

4. Content Providers merupakan Menangani masalah - masalah manajemen data dan database (kapalomen, 2016)

\subsubsection{Vuvoria SDK}

Vuforia merupakan package Software Development Kit (SDK) yang diperuntukan untuk membuat Augmented Reality. Vuforia menggunakan teknologi Computer Vision untuk mengenali dan melacak marker atau image target dan objek 3D sederhana secara real-time (Developer Vuforia, 2011).

\subsubsection{Blender 3D}

Blender adalah perangkat kreasi 3D yang bersifat gratis dan open source. Blender medukung seluruh alur kerja 3D seperi modeling, rigging, animasi, simulasi, rendering, compositing dan motion tracking, bahkan pengeditan video dan pembuatan game. Blender sangat cocok digunakan oleh perseorangan maupun oleh studio kecil yang bermanfaat dalam proyek 3D (Suratinoyo dkk, 2013).

\subsubsection{Android}

Android merupakan sistem operasi yang didistribusikan secara open source oleh Google, atau dengan kata lain operating system ini dapat dikelola oleh berbagai pihak tanpa membutuhkan lisensi khusus (Lee, 2012). Sistem operasi yang diperuntukan bagi smartphone ini berbasis sistem operasi Linux. Pada setiap versi Android memiliki versi API tersendiri, hingga pertanggal 19 Agustus 2015, Android telah merilis 23 tingkatan API. API (Application Programming Interface) merupakan sekumpulan perintah, fungsi, dan protokol yang dapat digunakan oleh programmer saat membangun perangkat lunak untuk sistem operasi tertentu (Lee, 2012).

\subsubsection{Alat Musik Tradisional Jawa Timur}

Indonesia memang terkenal dengan tempat wisatanya serta peninggalannya. Terutama pada Jawa Timur, salah satu provinsi yang terkenal dengan tempat wisata dengan panorama indah dan elok. Tak hanya itu, anda juga perlu mengetahui budaya heterogen dan tradisi leluhurnya yang wajib dilestarikan. Salah satunya adalah alat musik tradisional asal Jawa Timur. Alat musik Jawa Timur mempunyai beragam jenis alat musik. Mulai dari dipukul, dipetik, hingga digoyangkan (Dwi, 2020).

Terdapat beberapa jenis perangkat musik tradisi di Jawa Timur yang cukup menonjol diantaranya adalah alat musik Kongkil, Saronen, Gambus, dan Ordod. Penamaan dari masing-masing perangkat alat musik tersebut tampaknya diambil dari nama seni pertunjukan yang diiringinya. Masing-masing perangkat mempunyai jenis peralatan yang berbeda satu sama lain karena jenis seni pertunjukan yang diiringinyapun juga berbeda disamping berasal dari daerah yang terpisah antara satu dengan yang Iain nya (Soejono, 1995). Alat musik yang terdapat pada aplikasi ini antara lain Bonang, Kenong, Suling Bambu, Angklung Reog, Kendhang, Kendhang Jimbe, Kluncing, Saronen, Slompret, Kempul, TongTong, Ul-Dhaul, dan Kethuk Esri.

\section{METODE PENELITIAN}

\subsection{Metode}

Metode yang digunakan pada penelitian ini adalah Research and Development dengan tujuan mengembangkan aplikasi Pengenalan Alat Musik Tradisional Jawa Timur Menggunakan Teknologi Augmented Reality berbasis Android. Aplikasi ini dikembangkan berdasarkan hasil analisis masalah sesuai latar belakang masyarakat lebih menyukai alat musik modern dibandingkan alat musik tradisional karena kebanyakan masyarakat sekarang menilai alat musik tradisional dianggap jadul atau sudah ketinggalan zaman. Dengan adanya aplikasi ini, diharapkan dapat menimbulkan rasa ketertarikan bagi masyarakat untuk menghidupkan dan melestarikan alat musik tradisional.

\subsection{Analisis Kebutuhan}

\subsubsection{Analisis Kebutuhan Fungsional}

Kebutuhan fungsional pada penelitian ini adalah sebagai berikut :

1. Sistem dapat memindai / scan marker.

2. Sistem dapat mengeluarkan suara, melihat informasi penggunaan alat musik dan bisa zoom objek 3D.

\subsubsection{Analisis Kebutuhan Nonfungsional}

Kebutuhan nonfungsional pada penelitian ini adalah sebagai berikut :

1. Aplikasi bisa diakses melalui perangkat Android minimal v4.4 (kit-kat).

2. Aplikasi hanya mempunyai 4 menu, yaitu scan marker, Kuis, petunjuk penggunaan, about \& contact.

3. Aplikasi hanya bisa diakses oleh pengguna smartphone Android. 


\subsection{Perancangan Produk}

\subsubsection{Desain Flowchart Aplikasi}

Analisis sistem didefinisikan sebagai penguraian dari aplikasi dengan tujuan untuk mendefinisikan alur kerja dari apikasi tersebut agar aplikasi tersebut dapat berjalan sesuai dengan yang diinginkan. Analisa sistem dapat dilihat pada gambar 2 berikut.

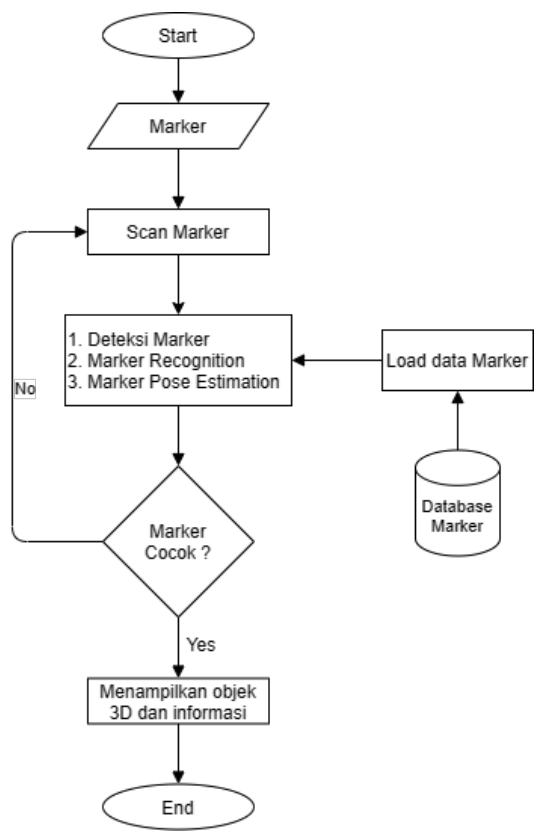

Gambar 2. Tampilan Flowchart Aplikasi

\subsubsection{Use Case Diagram}

Use Case Diagram atau diagram Penggunaan adalah diagram untuk menunjukan peran dari pengguna dan peran dalam menggunakan sistem seperti yang ditunjukan pada gambar 3. Penjelasan pada gambar 3 dimana aksi aktor atau sebagai pengguna aplikasi, pada saat aktor memilih menu Scan marker maka reaksi sistem akan menampilkan kamera lalu reaksi sistem akan menampilkan objek Augmented Reality sesuai marker tersebut.

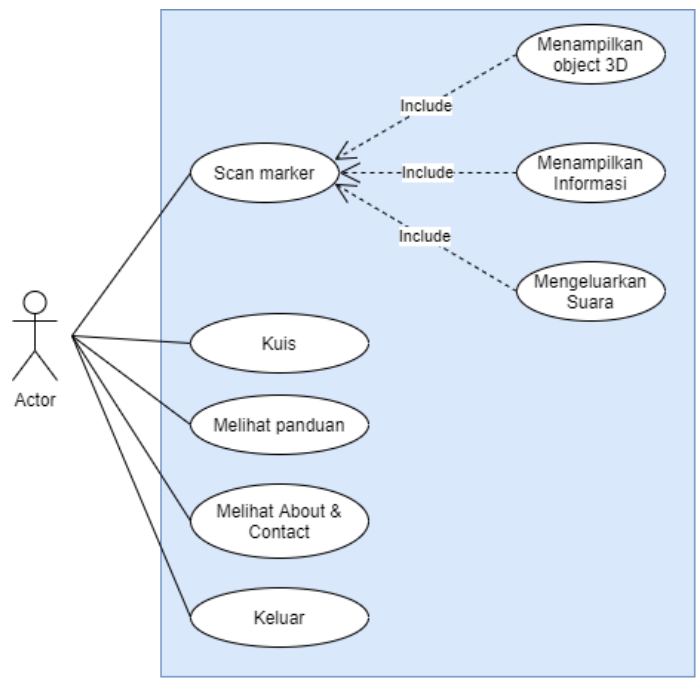

Gambar 3. Use Case Diagram

\subsubsection{Skema Aplikasi}

Skema atau gambaran umum dari perancangan sistem pada Aplikasi Pengenalan Alat Musik Tradisional Jawa Timur Menggunakan Teknologi Augmented Reality seperti berbasis Android yang ditunjukkan pada gambar 4.

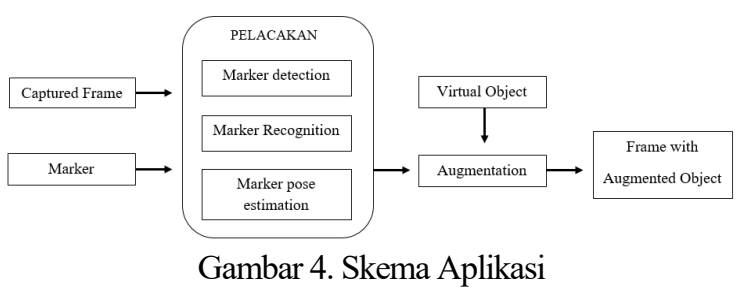

Pada gambar 4, pertama kita perlu memiliki gambar penanda atau marker. Modul pelacakan pada gambar diatas adalah inti dari sistem Augmented Reality. Pada modul pelacakan diatas adalah proses membaca marker atau penanda dari kamera, kemudian marker akan dilacak dan selanjutnya menghitung pose relatif kamera berdasarkan penanda yang terdeteksi dan dikenali. Yang dimaksud dengan "pose" adalah posisi enam derajat kebebasan (DOF), yaitu lokasi 3D dan orientasi 3D suatu objek. Kemudian komponen virtual ditambahkan sebagai bagian dari adegan nyata.

\section{HASIL DAN PEMBAHASAN}

\subsection{Implementasi Sistem}

Dari hasil analisis dan perancangan pada bab 3, diimplementasikan Aplikasi Pengenalan Alat Musik Tradisional Jawa Timur menggunakan Teknologi Augmented Reality berbasis Android. Hasil implementasi dari aplikasi yang dirancang, aplikasi dapat dioperasikan dan digunakan secara optimal.

1. Halaman Menu Utama

Pada halaman Menu Utama, terdapat 4 menu antara lain: Scan Marker, Kuis, Petunjuk Penggunaan, About \& Contact. Tampilan menu utama dapat dilihat pada gambar 5.

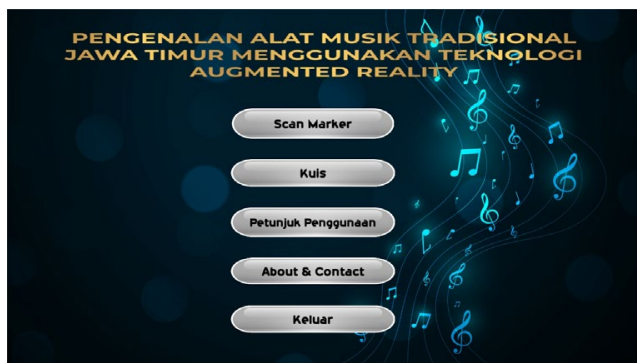

Gambar 5. Tampilan Menu Utama

\section{Halaman Scan Marker}

Pada menu Scan Marker ini, pengguna diharuskan untuk memindai marker yang telah di download pada halaman Petunjuk Penggunaan. Apabila ada marker yang terdeteksi, maka teks "Scan Marker Untuk Melihat Nama" akan berubah menjadi nama alat musik yang terdapat pada marker. 
Tampilan menu Scan Marker dapat dilihat pada gambar 6.

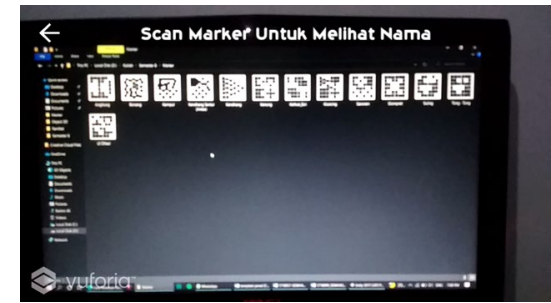

Gambar 6. Tampilan Menu Scan Marker

\section{Halaman Kuis}

Pada halaman ini terdapat beberapa macam soal, yaitu: tebak suara, pilihan ganda, dan essai. Pengguna harus menjawab semua pertanyaan yang telah di siapkan seperti yang terdapat pada gambar 7 .

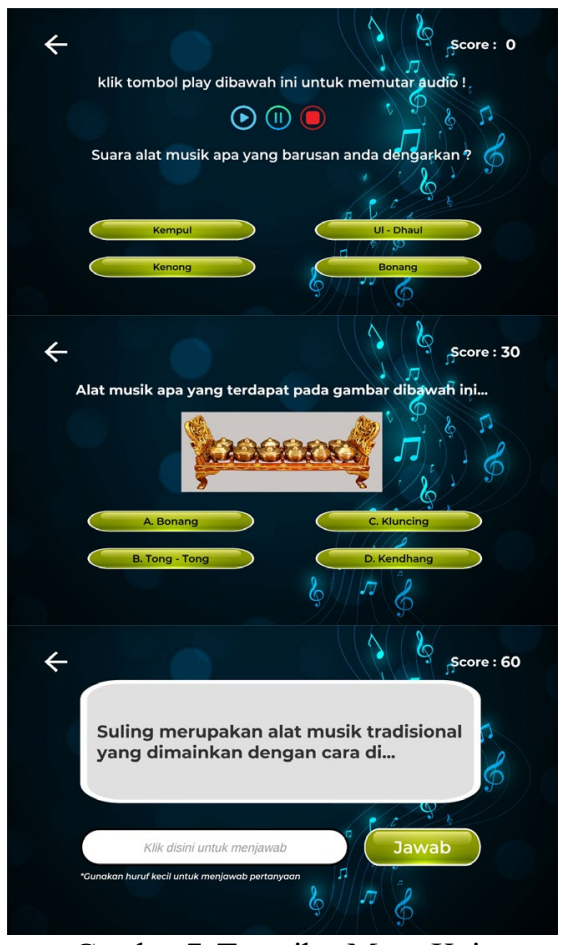

Gambar 7. Tampilan Menu Kuis

4. Halaman Petunjuk Penggunaan

Pada halaman ini terdapat petunjuk untuk meggunakan aplikasi, user diharuskan mengunduh marker dengan cara klik tombol Download Marker seperti pada gambar 8 .

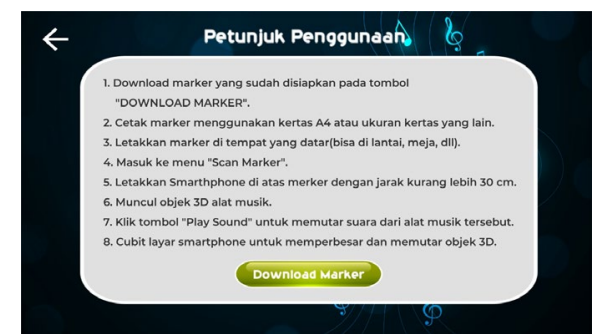

Gambar 8. Tampilan Menu Petunjuk Penggunaan

\section{Halaman About \& Contact}

Pada halaman ini terdapat info dan kontak penulis, user bisa klik icon sosial media untuk terhubung atau memberi masukan dan saran kepada penulis. Seperti yang terdapat pada gambar 9 .

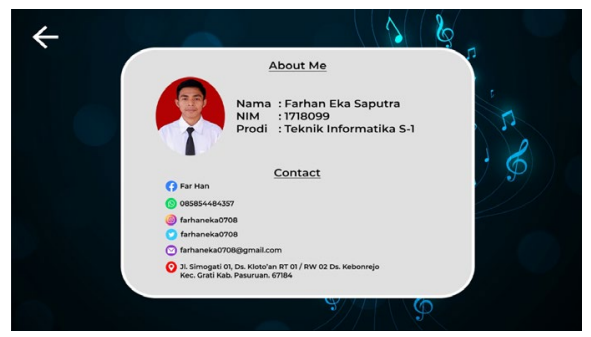

Gambar 9. Tampilan Menu About \& Contact

\subsection{Pengujian Sistem}

Pengujian sistem merupakan tahap uji coba sistem untuk menguji setiap fitur yang terdapat pada aplikasi agar dapat diambil kesimpulan apakah sistem berjalan dengan baik sesuai tujuan awal pembuatan aplikasi. Pengujian sistem terdiri dari :

\subsubsection{Pengujian Fungsional}

Pengujian fungsional sistem dilakukan untuk menguji fitur-fitur yang ada pada aplikasi. Hasil pengujian fungsional sistem ditunjukan dalam Tabel 1.

Tabel 1. Tabel Pengujian Fungsional

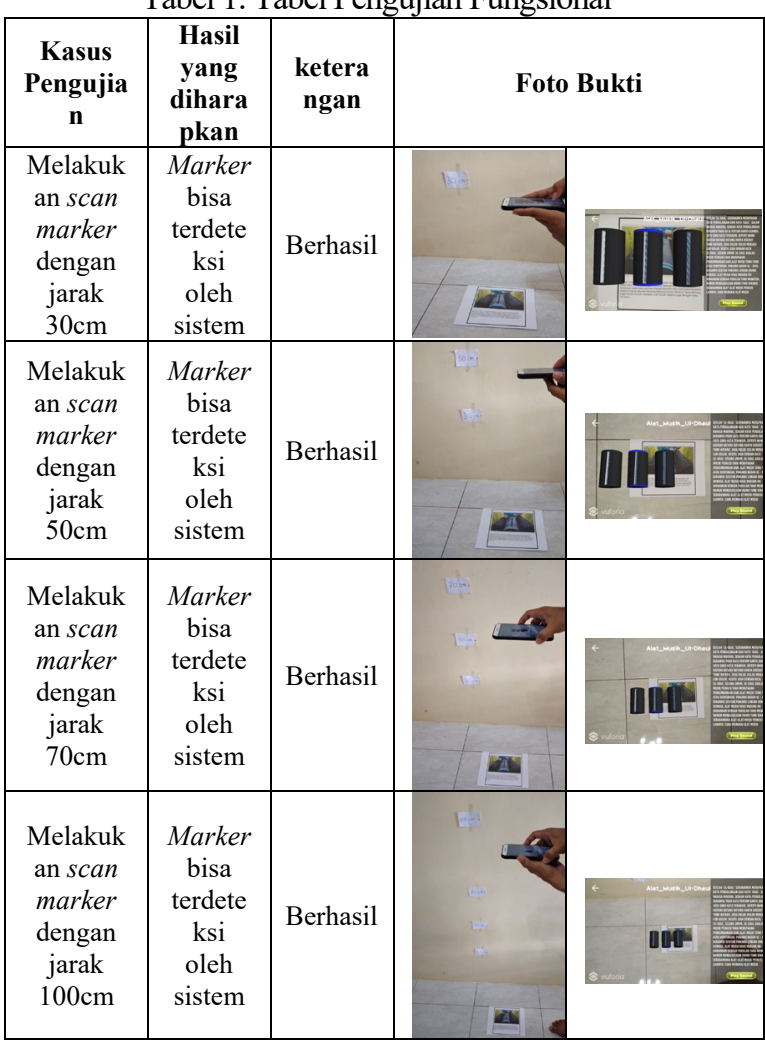




\begin{tabular}{|c|c|c|c|c|}
\hline $\begin{array}{c}\text { Melakuk } \\
\text { an scan } \\
\text { marker } \\
\text { dengan } \\
\text { jarak } \\
120 \mathrm{~cm}\end{array}$ & $\begin{array}{c}\text { Marker } \\
\text { bisa } \\
\text { terdete } \\
\text { ksi } \\
\text { oleh } \\
\text { sistem }\end{array}$ & $\begin{array}{c}\text { Tidak } \\
\text { berhasil }\end{array}$ & $\Delta$ & 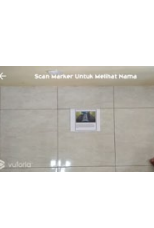 \\
\hline $\begin{array}{c}\text { Melakuk } \\
\text { an scan } \\
\text { marker } \\
\text { dengan } \\
\text { sudut } 90^{\circ}\end{array}$ & $\begin{array}{c}\text { Marker } \\
\text { bisa } \\
\text { terdete } \\
\text { ksi } \\
\text { oleh } \\
\text { sistem }\end{array}$ & Berhasil & 5 & \\
\hline $\begin{array}{c}\text { Melakuk } \\
\text { an scan } \\
\text { marker } \\
\text { dengan } \\
\text { sudut } 60^{\circ}\end{array}$ & $\begin{array}{c}\text { Marker } \\
\text { bisa } \\
\text { terdete } \\
\text { ksi } \\
\text { oleh } \\
\text { sistem } \\
\end{array}$ & Berhasil & 18 & 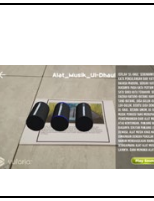 \\
\hline $\begin{array}{l}\text { Melakuk } \\
\text { an scan } \\
\text { marker } \\
\text { dengan } \\
\text { sudut } 30^{\circ}\end{array}$ & $\begin{array}{c}\text { Marker } \\
\text { bisa } \\
\text { terdete } \\
\text { ksi } \\
\text { oleh } \\
\text { sistem }\end{array}$ & $\begin{array}{c}\text { Tidak } \\
\text { Berhasil }\end{array}$ & 8 & - \\
\hline $\begin{array}{c}\text { Melakuk } \\
\text { an scan } \\
\text { marker } \\
\text { dengan } \\
\text { intensitas } \\
\text { cahaya } 4 \\
\text { lux } \\
\end{array}$ & $\begin{array}{c}\text { Marker } \\
\text { bisa } \\
\text { terdete } \\
\text { ksi } \\
\text { oleh } \\
\text { sistem }\end{array}$ & Berhasil & $\begin{array}{c}4 \\
4 \times 1 \\
\end{array}$ & \\
\hline $\begin{array}{c}\text { Melakuk } \\
\text { an scan } \\
\text { marker } \\
\text { dengan } \\
\text { intensitas } \\
\text { cahaya } \\
12 \text { lux }\end{array}$ & $\begin{array}{c}\text { Marker } \\
\text { bisa } \\
\text { terdete } \\
\text { ksi } \\
\text { oleh } \\
\text { sistem }\end{array}$ & Berhasil & \begin{tabular}{c|c}
12 \\
ux \\
\end{tabular} & \\
\hline $\begin{array}{c}\text { Melakuk } \\
\text { an scan } \\
\text { marker } \\
\text { dengan } \\
\text { intensitas } \\
\text { cahaya } \\
780 \text { lux } \\
\end{array}$ & $\begin{array}{c}\text { Marker } \\
\text { bisa } \\
\text { terdete } \\
\text { ksi } \\
\text { oleh } \\
\text { sistem }\end{array}$ & Berhasil & \begin{tabular}{c|c|}
780 \\
7 \\
\end{tabular} & \\
\hline
\end{tabular}

Berdasarkan hasil pungujian fungsional, semua menu dan fitur yang ada pada aplikasi Pengenalan Alat Musik Tradisional Jawa Timur menggunakan Teknologi Augmented Reality berbasis Android yang dibuat telah berhasil dan berjalan dengan optimal.

\subsubsection{Pengujian pada Smartphone}

Pengujian aplikasi pada Smartphone ini dilakukan dengan menggunakan tiga Smartphone dengan spesifikasi yang berbeda. Dimana pengujian ini dilakukan untuk mengetahui tingkat keberhasilan penggunaan aplikasi.

Hasil pengujian aplikasi dengan menggunakan tiga Smartphone dengan spesifikasi yang berbeda, semua tampilan dan fitur yang ada pada aplikasi dapat berjalan $100 \%$ pada tiga Smarthphone yaitu Samsung A20, Xiaomi Redmi 4X, dan Realme C12. Berikut adalah tabel hasil pengujian dari pembuatan aplikasi menggunakan tiga Smarthphone dengan spesifikasi berbeda yang ditunjukkan pada Tabel 2 .
Tabel 2. Tabel Pengujian Smarthphone

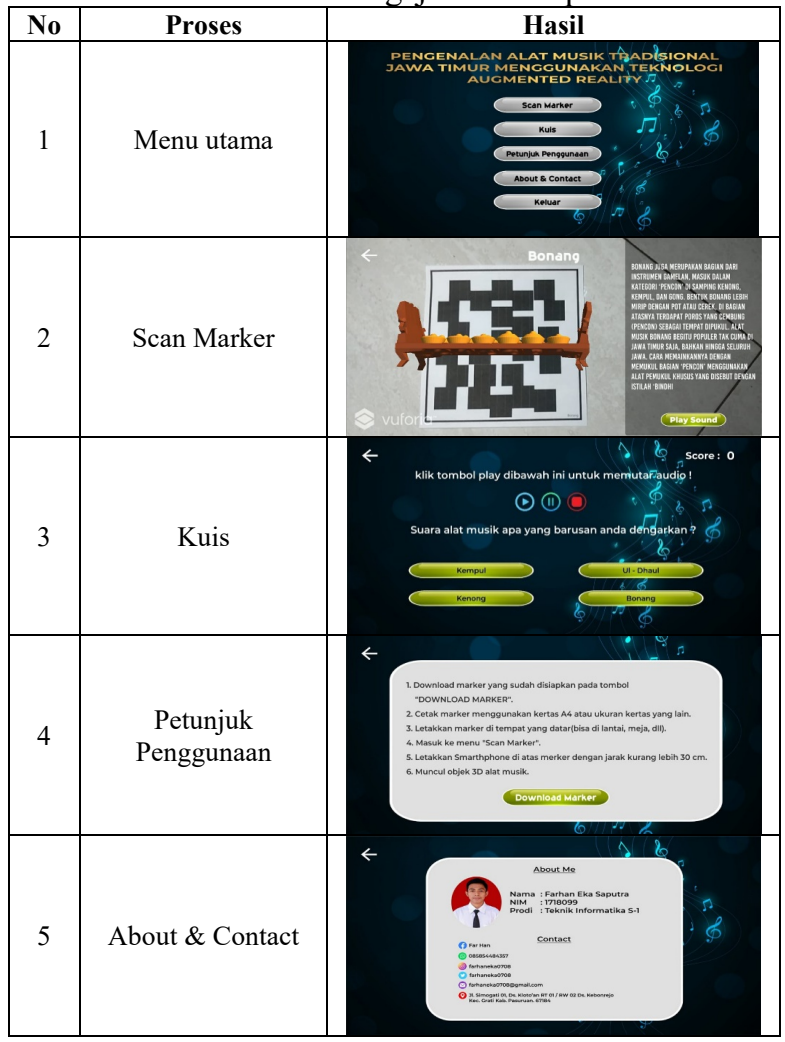

Berdasarkan Tabel 2, diketahui bahwa pengujian pada tiga Smartphone berjalan dengan baik dan semua fitur yang ada pada aplikasi dapat berjalan sesuai dengan tujuan awal.

\subsubsection{Pengujian User}

Pengujian user bertujuan untuk mengetahui apakah aplikasi sudah berjalan dengan baik atau belum. Pengujian dilakukan terhadap 20 responden yang terdiri dari siswa SDN KEBONREJO 1. Kuesioner berisi 10 pernyataan tentang aplikasi.

Dalam menentukan hasil persentase kuesioner menggunakan rumus mencari persentase hasil kuesioner seperti berikut (Sugiyono, 2008) :

$$
\rho=f / n \times 100 \text {. }
$$

dimana :

$$
\begin{aligned}
& p: \text { Presentase } \\
& f: \text { Jumlah jawaban } \\
& n: \text { Jumlah responden }
\end{aligned}
$$

Berdasarkan hasil dari pengisihan kuesioner yang sudah dilakukan oleh penulis dari responden dan dihitung dengan jumlah keseluruhannya mendapatkan persentase hasil seperti berikut, dapat dilihat pada Tabel 5 .

Tabel 5. Tabel Pengujian User

\begin{tabular}{|c|l|c|c|c|c|}
\hline \multirow{2}{*}{ No } & Pernyataan & $\begin{array}{c}\text { Sangat } \\
\text { Tidak } \\
\text { Setuju } \\
\text { (STS) }\end{array}$ & $\begin{array}{c}\text { Tidak } \\
\text { Setuju } \\
\text { (TS) }\end{array}$ & $\begin{array}{c}\text { Setuju } \\
\text { (S) }\end{array}$ & $\begin{array}{c}\text { Sangat } \\
\text { Setuju } \\
\text { (SS) }\end{array}$ \\
\hline 1 & $\begin{array}{l}\text { Performa } \\
\text { aplikasi sudah }\end{array}$ & $0 \%$ & $5 \%$ & $15 \%$ & $80 \%$ \\
\hline
\end{tabular}




\begin{tabular}{|c|c|c|c|c|c|}
\hline & maksimal & & & & \\
\hline 2 & $\begin{array}{l}\text { Waktu } \\
\text { scanning } \\
\text { marker tidak } \\
\text { lama }\end{array}$ & $0 \%$ & $0 \%$ & $5 \%$ & $95 \%$ \\
\hline 3 & $\begin{array}{l}\text { Responsivitas } \\
\text { aplikasi sudah } \\
\text { baik }\end{array}$ & $0 \%$ & $0 \%$ & $25 \%$ & $75 \%$ \\
\hline 4 & $\begin{array}{l}\text { Tampilan } \\
\text { background, } \\
\text { menu dan } \\
\text { tombol sudah } \\
\text { baik }\end{array}$ & $0 \%$ & $5 \%$ & $25 \%$ & $70 \%$ \\
\hline 5 & $\begin{array}{l}\text { Fitur kuis yang } \\
\text { ada pada } \\
\text { aplikasi mudah } \\
\text { dimengerti }\end{array}$ & $0 \%$ & $0 \%$ & $15 \%$ & $85 \%$ \\
\hline 6 & $\begin{array}{l}\text { Tapilan object } \\
\text { 3D terlihat jelas }\end{array}$ & $0 \%$ & $5 \%$ & $10 \%$ & $85 \%$ \\
\hline 7 & $\begin{array}{l}\text { Tidak } \\
\text { membutuhkan } \\
\text { cahaya yang } \\
\text { sangat terang } \\
\text { agar marker } \\
\text { dapat terdeteksi }\end{array}$ & $0 \%$ & $5 \%$ & $10 \%$ & $85 \%$ \\
\hline 8 & $\begin{array}{l}\text { Suara alat } \\
\text { musik } \\
\text { terdengar } \\
\text { dengan jelas }\end{array}$ & $0 \%$ & $15 \%$ & $20 \%$ & $65 \%$ \\
\hline 9 & $\begin{array}{l}\text { Marker dapat } \\
\text { terdeteksi } \\
\text { dengan jarak } \\
>30 \mathrm{~cm} \text { dan } \\
<100 \mathrm{~cm}\end{array}$ & $0 \%$ & $0 \%$ & $5 \%$ & $95 \%$ \\
\hline 10 & $\begin{array}{l}\text { Marker dapat } \\
\text { terdeteksi pada } \\
\text { semua sudut }\end{array}$ & $0 \%$ & $0 \%$ & $0 \%$ & $100 \%$ \\
\hline
\end{tabular}

Hasil pengujian yang ditunjukkan pada Tabel 5 menunjukkan bahwa Aplikasi Pengenalan Alat Musik Tradisional Jawa Timur menggunakan Teknologi Augmented Reality berbasis Android ini secara keseluruhan dapat dikatakan sudah baik dan sesuai dengan tujuan awal.

\section{KESIMPULAN DAN SARAN}

\subsection{Kesimpulan}

Kesimpulan yang dapat diuraikan dari hasil pembuatan aplikasi pengenalan alat musik tradisional Jawa Timur yaitu:

1. Berdasarkan langkah-langkah metode pengembangan yang dilakukan, diketahui bahwa aplikasi pengenalan alat musik tradisional Jawa Timur menggunakan Teknologi Augmented Reality berbasis Android berhasil dikembangkan.

2. Berdasarkan hasil pengujian fungsional, aplikasi pengenalan alat musik tradisional Jawa Timur menggunakan Teknologi Augmented Reality berbasis Android dapat dioperasikan dan digunakan secara optimal.

3. Berdasarkan hasil pengujian Smarthphone pada aplikasi pengenalan alat musik tradisional Jawa Timur menggunakan Teknologi Augmented Reality berbasis Android yang telah dilakukan mendapatkan hasil bahwa semua tombol, menu dan fitur dapat berjalan dengan baik.

\subsection{Saran}

Untuk pengembangan kedepan yang lebih baik, aplikasi pengenalan alat musik tradisional Jawa Timur ini memiliki beberapa saran, yaitu

1. Aplikasi ini bisa ditambahkan fitur-fitur menarik yang lainnya.

2. Aplikasi ini bisa dikembangkan dengan cara Markless Augmented Reality.

3. Aplikasi ini bisa dikembangkan dengan multiple marker / multi target.

\section{DAFTAR PUSTAKA}

[1] Priyo. Pengertian Augmented Reality - Sistem Knowledge Management TIK. (Online), http://solmet.kemdikbud.go.id/?p=2895, diakses 10 Maret 2021

[2] Situs Itgenic. 2020. Mengupas Kelebihan dan Kekurangan AR. (Online), https://itgenic.co.id /mengupas-kelebihan-dan-kekurangan-ar/, diakses 31 Maret 2021

[3] Situs Pendidik. 2020. V Pengertian Alat Musik, Fungsi, Contoh \& Jenisnya (Lengkap). (Online), www.pendidik.co.id/alat-musik/, diakses 31 Maret 2021

[4] Dwi. 2020. 18 Alat Musik Jawa Timur dan Cara Memainkannya.

(Online), https://tambahpinter.com/alat-musik-tradisionaljawa-timur/, diakses 31 Maret 2021

[5] Soejono, S. 1995. ALBUM ALAT MUSIK TRADISIONAL.

(Online), http://repositori.kemdikbud.go.id/7450/, diakses 1 April 2021

[6] Ajim, N. 2015. Alat Musik Tradisional dan Modern. (Online), https://www.mikirbae.com/ 2015/04/alat-musik-tradisional-danmodern.html, diakses 31 Maret 2021

[7] Kapalomen. 2016. ANDROID - KOMPONEN APLIKASI ANDROID. (Online), http://www.kapalomen.com/2016/11/androidkomponen-aplikasi-android.html, diakses 31 Maret 2021

[8] Zebua dkk. 2020. "Pengenalan Dasar Aplikasi Blender 3D dalam Pembuatan Animasi 3D". Jurnal ABDIMAS Budi Darma

[9] Zwingly dkk. 2018. "Penerapan Augmented Reality Berbasis Android Untuk Mengenalkan Pakaian Adat Tountemboan". E-Journal Teknik Informatika Vol. 13

[10] Markho dkk. 2016. "Augmented Reality Pada Aplikasi Android Untuk Memperlihatkan Gedung Fatek". E-Journal Teknik Elektro dan Komputer Vol. 5 No.1

[11] Ulfa dkk. 2017. Studi Tentang Alat Musik Tradisional Sumatera Selatan Pada Pendidikan Anak Usia Dini (PAUD). (Online), diakses 14 Juni 2021

[12] Waskito, aziz. 2018. Seminar Nasional FST 2018. (Online), https://semnas.unikama .ac.id/senastek/unduhan/2018/308441162.pdf, diakses 14 Juni 2021 
[13] Hirzi, A. T. 2007. Mengomunikasikan Musik kepada Anak. MediaTor Vol.8 No. 2

[14] Khotimah, Khusnul. 2014. Aplikasi Tutorial Rukun Umroh Menggunakan Augmented Reality Berbasis Android, prosiding seminar ilmiah nasional, 8 (10):2302-3740.

[15] Oktavia dkk. 2019. Metode marker berdasarkan dari teknologi Augmented Reality dihadirkan dari gabungan teknologi computervision dan image processing yang mencari informasi dari sebuah gambar secara langsung. Jurnal Ilmiah Teknologi Informasi Asia Vol.13, No.1

[16] Sugiyono, S. 2008. Metode Penelitian Kuantitatif, Kualitatif dan R\&D. Bandung: Alfabeta.

[17] Suratinoyo, dkk. 2013. "Cerita Rakyat Daerah Minahasa: Implementasi Short Film Animasi 3D”. E-jurnal Teknik Informatika Universitas Sam Ratulangi Universitas Sam Ratulangi, vol 2 , no. 2
[18] Kurniawan dkk. 2011. Aplikasi Penjualan dengan Program Java Netbeans, Xampp, dan iReport. Jakarta: PT Elex Media Komputindo.

[19] Yuni, Q. F. 2016. Kreativitas Dalam Pembelajaran Seni Musik Di Sekolah Dasar: Suatu Tinjauan Konseptual. ELEMENTARY Vol. 4, No. 1

[20] Lee, W. M. 2012. Beginning Android 4 Application Development. Indianapolis: John Wiley \& Sons, Inc.

[21] Developer Vuforia. 2011. Developing with Vuforia. https://developer.vuforia.com/ resources/dev-guide/getting- started, Diakses 29 Maret 2021

[22] Azuma, R. T. 1997. A Survey of Augmented Reality. In Presence: Teleoperators and Virtual Environments, 2.

[23] Billinghurts, Mark. 2002. Augmented Reality in Education, New horizons for learning 12:1-2 